\title{
Synthesis and Characterization of Adsorbent for Pb(II)-capture by using Glow Discharge Electrolysis Plasma
}

\author{
Jinzhang Gao, ${ }^{*}$ Youdi Wang, Wu Yang, and Yan Li \\ Chemistry \& Chemical Engineering College, Northwest Normal University, Lanzhou 730070, P. R. China \\ *E-mail: jzgao@nwnu.edu.cn \\ Received October 27, 2009, Accepted January 4, 2010
}

\begin{abstract}
A novel polyacrylamide grafted hydrous ferric oxide adsorbent composite has been synthesized by using glow discharge electrolysis plasma. To optimize the synthesis conditions, the following parameters were examined in detail: applied power, discharge time, post polymerization temperature, post polymerization time, amount of crosslinking agent and hydrous ferric oxide gel added and so on. The adsorbent was characterized by Fourier transform infrared spectroscopy (FT-IR) and X-ray photoelectron spectroscopy (XPS). The removal percentage of the adsorbent in $\mathrm{Pb}$ (II) solution was examined and the data obtained showed that the adsorbent composite has a high capacity for lead ion. For the use in wastewater treatment, the thermodynamic and kinetic of $\mathrm{Pb}$ (II)-capture were also studied. Results indicated that the adsorption reaction was a spontaneous and an endothermic process, and it seems to be obeyed a pseudo-secondorder rate model. Moreover, the adsorption isotherm of $\mathrm{Pb}(\mathrm{II})$-capture is following the Langmuir and Freundlich isotherm models.
\end{abstract}

Key Words: Glow discharge electrolysis plasma, Lead ion, Adsorbent, Thermodynamics and kinetics, Adsorption isotherm

\section{Introduction}

Owing to $\mathrm{Pb}(\mathrm{II})$ being a non-biodegradable and enrichment substance in human-body, the $\mathrm{Pb}$-pollution to environment is a serious problem, even at low concentration. Thus, the removal of lead ion from water or soil is still an important project. Commonly used methods for removing dissolvable lead ion are below: chemical precipitation, electrochemical treatment, ion exchange, filtration, electrodeposition, solvent extraction, biological systems, and adsorption, in which each has its own advantage and shortcoming. ${ }^{1-4}$ Because the characteristic of adsorption technique for the use in water treatment is simple in operation and cheap in price, the synthesis of new adsorbent has received more interesting.

Adsorption of metal ions occurs as a result of physicochemical interaction, mainly ion exchange or complex formation between metal ions and the functional groups present in the adsorbent surface. Thereby, adsorbents with proper functional groups play a vital role in the adsorption performance. Various functional groups such as hydroxyl, thio, iminodiacetic and amine functional groups have been adopted in adsorbents, in which the nitrogen-containing functional group has been found to be one of the most effective functionalities in the adsorption or removal of heavy metal ions. 5,6

Glow discharge electrolysis is a kind of non-equilibrium plasma, which can provide a lot of energetic species such as $\cdot \mathrm{OH}$, $\cdot \mathrm{H}$, and $\mathrm{HO}_{2} \cdot$. Sengupta et al. ${ }^{7}$ found that the yield of $\cdot \mathrm{OH}$ radical was more than $12 \mathrm{~mol}$ for the passage of per mole electron of electricity in glow discharge electrolysis. The chemical yield exceeded the theoretical value observed on the basis of Faraday's law. In other words, glow discharge electrolysis can be considered as a rich source of free radical in aqueous solution, which could be applied to induce some unusual chemical chang- es in solution. ${ }^{8,9}$ So far, this technique has been studied widely in the field of wastewater treatment and gotten many potential applications. ${ }^{10-13}$ However, relatively few papers are devoted to synthetic chemistry, that is, how to use these energetic species to initiate a formation reaction. As far back as the 1970s, Harada et al. ${ }^{14,15}$ found firstly the formation of some amino acids during the contact glow discharge process in aqueous solution containing aliphatic carboxylic acid or elemental carbon. Since then, Sengupta et al. ${ }^{16}$ taking the technique as a new tool examined in detail the acrylamide polymerization. Gao and his co-work$\mathrm{ers}^{17-20}$ synthesized successfully the oxalic acid from formic acid and some superabsorbent composites by means of this technique rather than using chemical initiators. That is to say, the technique of glow discharge electrolysis plasma (GDEP) can be used in synthetic chemistry to initiate radical reactions. Moreover, it differs from gaseous plasma that the generation of GDEP is not need the high voltage and high vacuum apparatus and the operation very easy.

In this paper, the polyacrylamide grafted hydrous ferric oxide adsorbent composite was synthesized by aqueous solution polymerization with the glow discharge electrolysis plasma. The polymerization conditions were investigated in detail. The goal of this study was to evaluate the potential of the composite for adsorption of lead ion from solution. Thermodynamic and kinetic studies of lead ion solution were performed and the capacity data were also correlated to the standardized isotherm model.

\section{Experimental}

All chemicals used were of analytical grade or HPLC grade. Acrylamide was re-crystallized thrice from acetone. Doubledistilled water was used throughout. The experimental apparatus consists of a high voltage power supply and a reactor. The power 
supply was a Model of LW100J1 DC power supply (Liyou, Shanghai, China) providing the voltage of $0 \sim 1000 \mathrm{~V}$ and the current of $0 \sim 1 \mathrm{~A}$. The reactor was a $250 \mathrm{~mL}$ four-necked flask equipped a reflux condenser and a nitrogen conduit, a platinum wire anode with a diameter of $0.5 \mathrm{~mm}$ sealed into a glass tube to generate glow discharge plasma in aqueous solution and a graphite cathode with a diameter of $10 \mathrm{~mm}$. There was a magnetic stirring bar at the bottom of the flask to keep the solution mixed well.

Acrylamide was examined by means of a high-performance liquid chromatography (Shimadzu HPLC-LC-6A) equipped with a spectrophotometric UV/V detector (Shimadzu-SPD$6 \mathrm{AV})$ and a Kromasil 100-5 C18 column $(250 \times 4.6 \mathrm{~mm})$. The infrared spectra of polyacrylamide grafted hydrous ferric oxide adsorbent were recorded in the range of $4000-400 \mathrm{~cm}^{-1}$ on a DIGILAB FTS 3000 FT-IR spectrophotometer (USA) with KBr pellet. A thermostat water shaker (WHY-2S, Changzhou Chenghui Instrument Factory, China) was used at room temperature. The $\mathrm{pH}$ was measured by a $\mathrm{pH}$ meter (pHS-25 B, Shanghai Dapu Instrumental Factory, China). The information about chemical binding of $\mathrm{Pb}(\mathrm{II})$ on the surface of adsorbent was ascertained by X-ray photoelectron spectroscopy (XPS) (Physical electronics division, USA) equipped with a twin anode $(\mathrm{Mg} \mathrm{K} \alpha / \mathrm{Al} \mathrm{K} \alpha)$ source under a $10^{-8} \mathrm{~Pa}$ residual pressure. Surface charging effects were corrected with $\mathrm{C} 1 \mathrm{~s}$ peak at $284.6 \mathrm{eV}$ as a reference. The adsorption capacity of metal ion was obtained from the initial and the final concentration of metal ion determined by atomic adsorption spectrophotometer (Hitachi 180 - 80, Japan).

Hydrous ferric oxide gel was prepared by adding ammonia into ferric chloride solution until $\mathrm{pH}=7.0$. The resulting precipitate was dried under low temperature and then grafted with polyacrylamide using the following procedure: $5 \mathrm{~g}$ of acrylamide and $0.5 \mathrm{~g}$ of $\mathrm{N}, \mathrm{N}$-methylenebisacrylamide were first mixed in $70 \mathrm{~mL}$ of degased $\mathrm{Na}_{2} \mathrm{SO}_{4}$ solution $(2 \mathrm{~g} / \mathrm{L})$ and then, $1.5 \mathrm{~g}$ of hydrous ferric oxide gel was added to the mixture with stirring. The discharge with $540 \mathrm{~V}$ and $75 \pm 5 \mathrm{~mA}$ was lasting for $14 \mathrm{~min}$. Finally, the mixture was heated at $85{ }^{\circ} \mathrm{C}$ under $\mathrm{N}_{2}$ ambient for additional 150 min which was called the post polymerization reaction. The resulting product was dewatered and washed with methanol, and dried at $65^{\circ} \mathrm{C}$ for getting a constant weight. The product was milled and screened to select the particles between $100-900 \mu \mathrm{m}$ for this study.

All experiments for the adsorption were carried out by the following procedure, unless otherwise stated. About $0.1 \mathrm{~g}$ of adsorbent was shaken with $100 \mathrm{~mL}$ solution containing metal ions at $298 \mathrm{~K}$ and $150 \mathrm{rpm}$ with a mechanical shaker. The $\mathrm{pH}$ of solution was adjusted by using $0.05 \mathrm{M}$ solution of $\mathrm{HNO}_{3}$ and $\mathrm{NaOH}$. After centrifuging and separating, the metal ion in adsorbent was analyzed by using atomic absorption spectrophotometer. The adsorption capacity $\left(Q_{e}\right)$ was calculated by the following equation:

$$
Q_{e}=\frac{\left(C_{o}-C_{e}\right)}{W}
$$

Where $C_{o}$ is the initial concentration of metal ion $(\mathrm{mg} / \mathrm{mL})$, $C_{e}$ is the final concentration of metal ion $(\mathrm{mg} / \mathrm{mL}), V$ is the volume of metal ion solution $(\mathrm{mL})$ and $W$ is the weight of the adsorbent (g) used. All the adsorption experiments were performed in triplicate to observe the reproducibility and the mean value was used for each set of values.

The effects such adsorbent mass, initial lead ion concentration, $\mathrm{pH}$ and particle size of adsorbent on adsorption for lead ion were examined. Artificial wastewater solution $(500 \mathrm{mg} / \mathrm{L}$ $\mathrm{Pb}(\mathrm{II})$ ) was prepared by dissolving analytical grade lead acetate in distilled water, and diluted to the desired concentration before the use. Batch adsorption tests were conducted by mixing a given weight of adsorbent and $100 \mathrm{~mL}$ of wastewater containing lead ion at $\mathrm{pH}=5.0$ for $240 \mathrm{~min}$. The size of adsorbent particles was selected in the range from 450 to $600 \mu \mathrm{m}$.

In the range of $100-500 \mathrm{mg} / \mathrm{L} \mathrm{Pb}(\mathrm{II})$, the adsorption isotherm experiments were performed by adding $0.1 \mathrm{~g}$ of polyacrylamide grafted hydrous ferric oxide adsorbent into the lead ion solution. The mixture was shaken for $240 \mathrm{~min}$ to reach equilibrium at $\mathrm{pH} 5.0$ and $298 \mathrm{~K}$. The mixture solution was filtered and the determination of $\mathrm{Pb}$ (II) content was carried out.

Thermodynamic parameters for the adsorption process were examined on the batch adsorption of $100.0 \mathrm{mg} / \mathrm{L} \mathrm{Pb}$ (II) at the temperature ranging from 283 to $318 \mathrm{~K}$, shaking for $240 \mathrm{~min}$ to reach equilibrium. After determining $\mathrm{Pb}(\mathrm{II})$, the percent removal was calculated. The kinetic study was carried out by using $0.1 \mathrm{~g}$ adsorbent in $100 \mathrm{~mL}$ of $\mathrm{Pb}$ (II) solution at $\mathrm{pH} 5.0$ and $298 \mathrm{~K}$ during different time interval from 20 to $300 \mathrm{~min}$.

Single component $1000 \mathrm{mg} / \mathrm{L}$ of stock solution was prepared by using their corresponding nitrate, such as $\mathrm{Cu}(\mathrm{II}), \mathrm{Co}(\mathrm{II})$, $\mathrm{Ni}(\mathrm{II}), \mathrm{Ag}(\mathrm{I}), \mathrm{Cd}(\mathrm{II})$ and $\mathrm{Pb}(\mathrm{II})$, separately. Working solution was diluted to a desired concentration before the use. Multi-component adsorption was tested by using $600 \mathrm{~mL}$ of the mixed solution with $0.1 \mathrm{~g}$ adsorbent, in which each ion concentration was $50 \mathrm{mg} / \mathrm{L}$.

Acrylamide stock solution ( $3 \mathrm{mg} / \mathrm{mL}$ ) was prepared by dissolving a desired amount of acrylamide in the mixed solution containing $40 \mathrm{~mL}$ isopropyl alcohol, $450 \mathrm{~mL}$ deionized water and $10 \mathrm{~mL}$ enthanol, and then, was diluted to working solution and stored in amber bottle. Likewise, adsorbent of $0.1 \mathrm{~g}$ was added to $10 \mathrm{~mL}$ of the above solution. After shaking for $4 \mathrm{~h}$ and filtering through a $0.22 \mathrm{~mm}$ polytetrafluoroethylene (PTFE) syringe filter, the filtrate was determined directly by HPLC. The used conditions were below: flow rate was $0.9 \mathrm{mLmin}^{-1}$; detection wavelength $205 \mathrm{~nm}$.

\section{Results and Discussion}

Because the adsorbent was prepared by glow discharge electrolysis plasma rather than chemical initiator, the optimum conditions should be re-selected again. Generally, the variables affecting the polymerization could be divided roughly into two parts, in which one comes from the plasma source such as applied power and discharge time; others are alike the common polymerization, i.e., post polymerization temperature, post polymerization time, amount of cross linking-agent and hydrous ferric oxide gel added and so on. Here the adsorption capacity was chosen as a quality standard to evaluate the polymerization reaction. It is not easy to offer an accurate explanation for every test, because there are a lot of energetic species in the plasma. In other words, it is not only a radical polymerization reaction. 


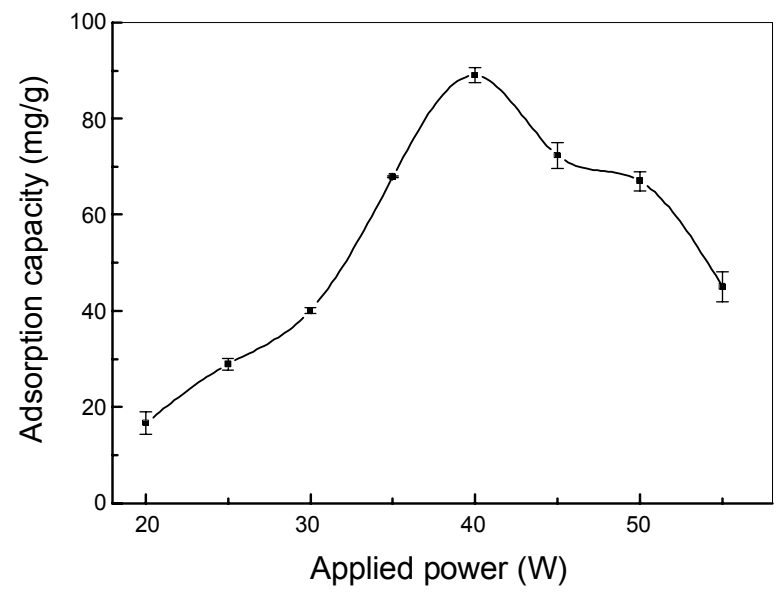

Figure 1. Effect of applied power

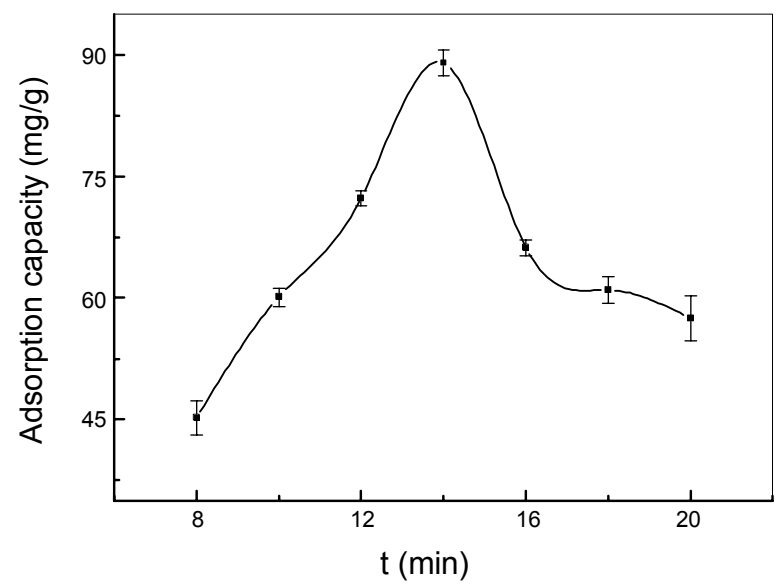

Figure 2. Effect of discharge time

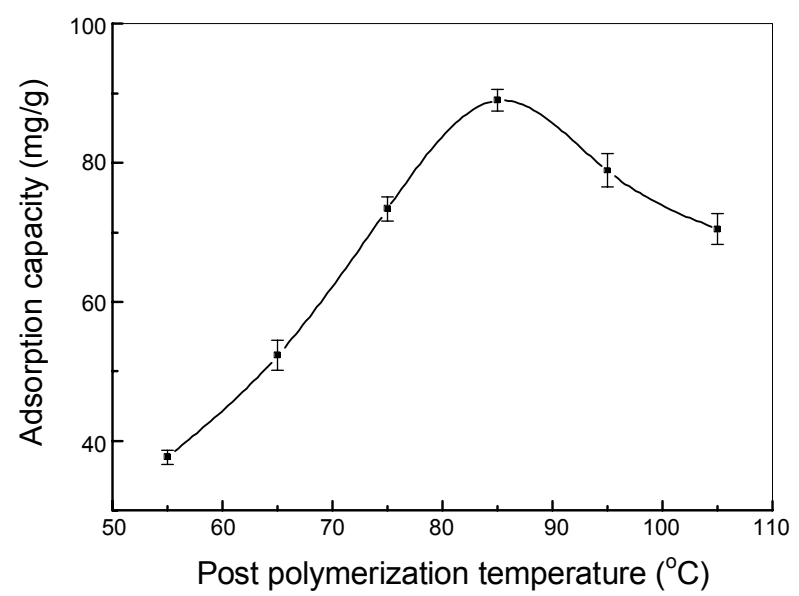

Figure 3. Effect of post polymerization temperature

Just as shown in Fig. 1, the adsorption capacity increases sharply with the increase of the applied power up to $40 \mathrm{~W}$, and then decreases gradually. This is attributed to the fact that at the beginning the increase of energetic species is benefit to polymerization of acrylamide monomer. With reaction time prolonging the amount of acrylamide monomer was decreased, offering

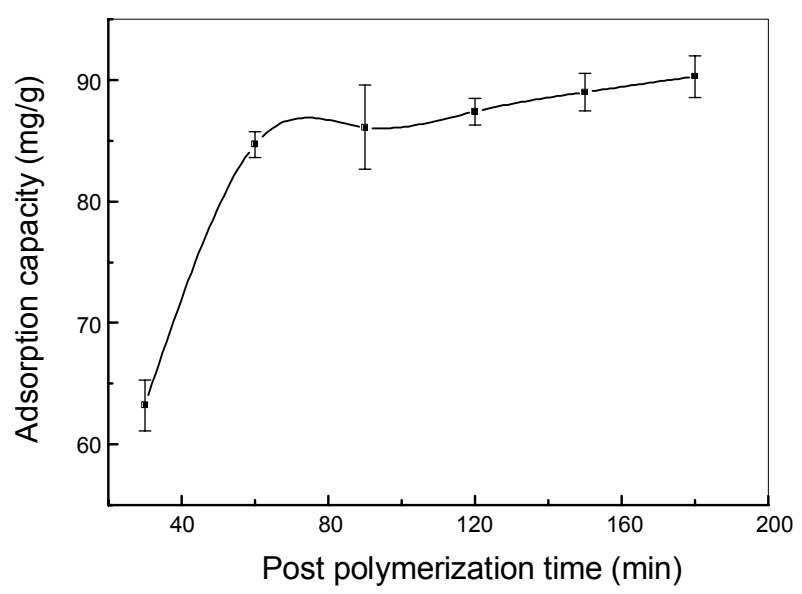

Figure 4. Effect of post polymerization time

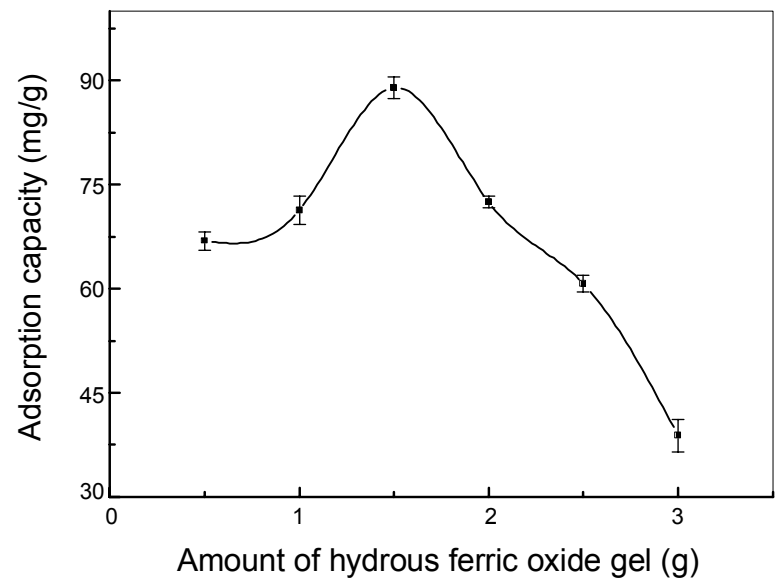

Figure 5. Effect of the amount of hydrous ferric oxide gel

more collision between energetic species and polymer to destroy the polymer. Thereby, $40 \mathrm{~W}$ of power was chosen in this study.

It can be seen from Fig. 2, the adsorption capacity of adsorbent composite increases with increasing discharge time from $8 \mathrm{~min}$ to $14 \mathrm{~min}$. Over $14 \mathrm{~min}$, the adsorption capacity decreases. The reason may be as same as explanation in section Fig. 1.

It is well-known that raising temperature can speed the polymerization as showing in Fig. 3. Over $85^{\circ} \mathrm{C}$ the adsorption capacity decreases due to perhaps the change of polymer structure, for example, a compact structure with smaller pores. However, the longer the post polymerization time, the larger the adsorption capacity is (see Fig. 4). To economize resource, 150 min was enough in this work. Due to the limit of solubility of hydrous ferric oxide gel in aqueous, the graft polymerization with polyacrylamide seems to be a heterogeneous reaction. Just as Fig. 5 shown the excess of hydrous ferric oxide gel is not suitable for polymerization. Commonly, the adsorbent should exhibit somewhat both rigidity and swelling for removing metal ions from aqueous solution. This character relies strongly on the amount of cross linking-agent used in the polymerization reaction. More than or less than a critical amount of cross linking-agent would decrease the adsorption capacity of adsorbent composite. It can be seen from Fig. 6 that $0.6 \mathrm{~g}$ cross linking-agent was appro- 


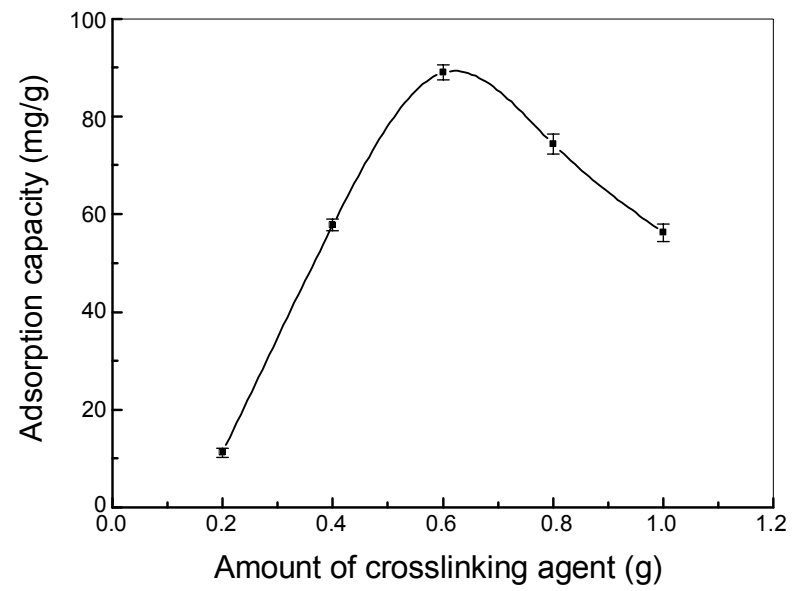

Figure 6. Effect of the amount of cross linking agent

(a)

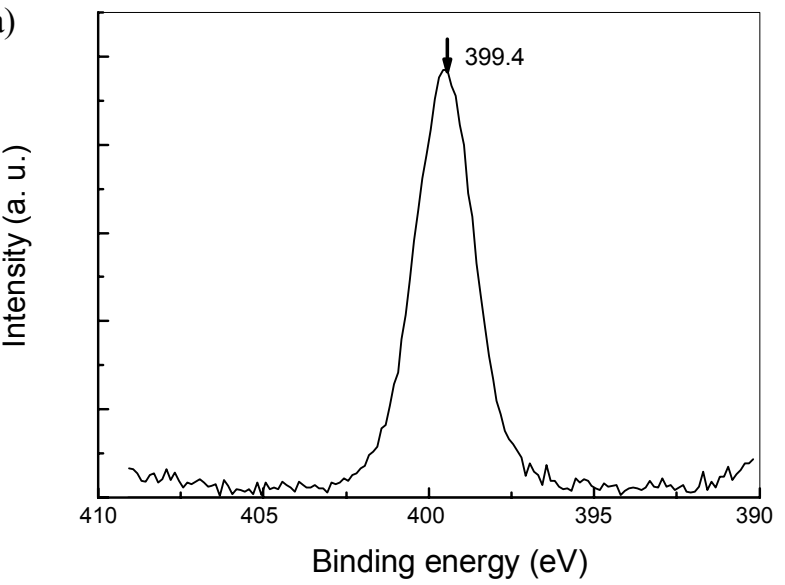

(c)

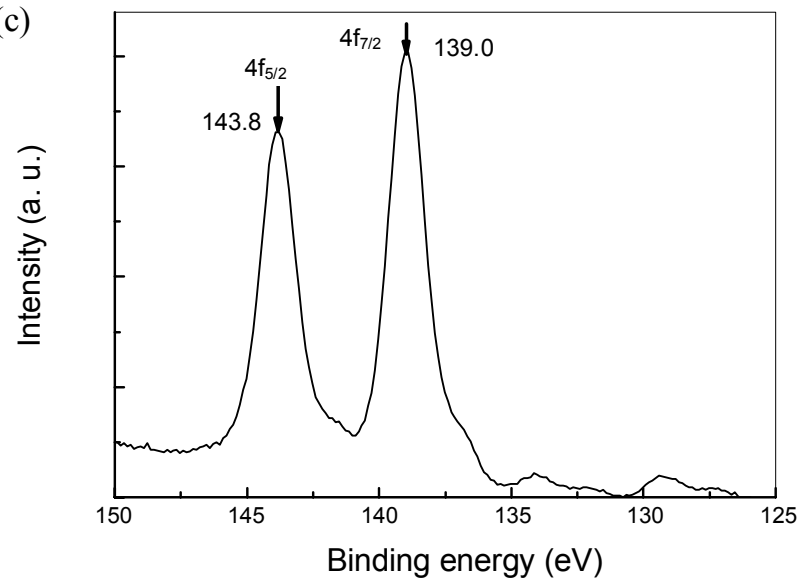

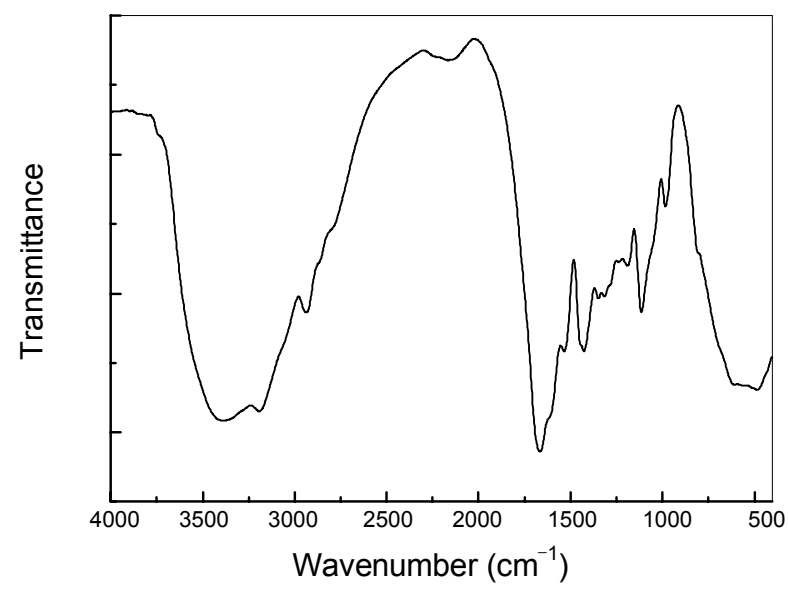

Figure 7. FT-IR spectra of polyacrylamide grafted hydrous ferric oxide adsorbent

(b)

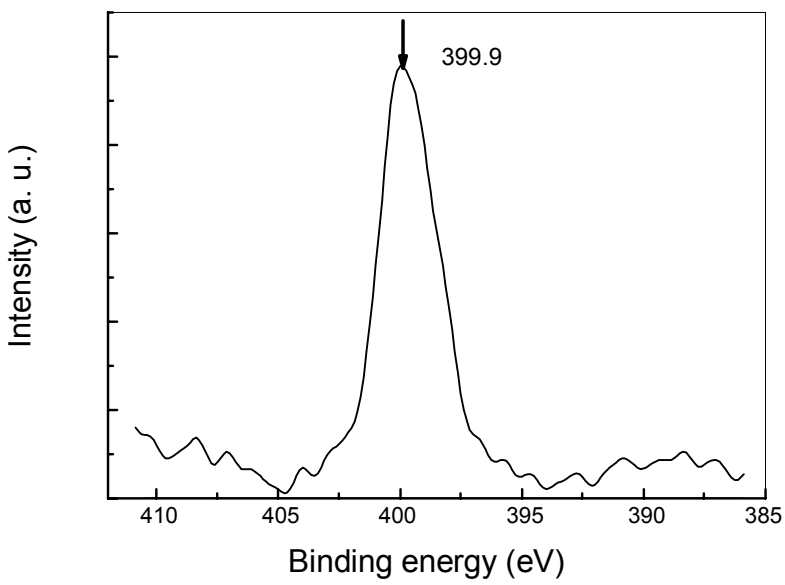

(d)

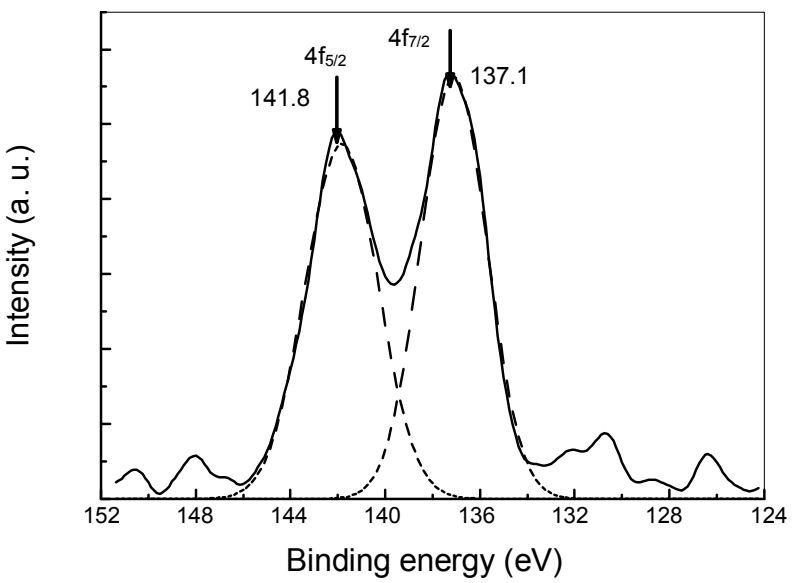

Figure 8. (a) N1s XPS spectrum of the adsorbent before Pb(II) adsorption; (b) N1s XPS spectrum of the adsorbent after Pb(II) adsorption; (c) $\mathrm{Pb} 4 \mathrm{f}_{7 / 2}$ and $\mathrm{Pb} 4 \mathrm{f}_{5 / 2}$ XPS spectrum of pure lead acetate; (d) $\mathrm{Pb} 4 \mathrm{f}_{7 / 2}$ and $\mathrm{Pb} 4 \mathrm{f}_{5 / 2}$ XPS spectrum of the adsorbent after Pb(II) adsorption.

priate.

The FT-IR spectrum of polyacrylamide grafted hydrous ferric oxide adsorbent was recorded in the range of $4000-400$ $\mathrm{cm}^{-1}$, showing in Fig. 7. The broad spectrum around $3388 \mathrm{~cm}^{-1}$ represents the overlap of $\mathrm{O}-\mathrm{H}$, which is the sum of contribution from water and hydroxyl bonding to ferric oxide, and N-H sym- metric stretching vibrations absorption in an acyl $\left(-\mathrm{CONH}_{2}\right)$ group. The peak at $1113 \mathrm{~cm}^{-1}$ is assigned to $\mathrm{C}-\mathrm{O}$ stretching vibration. The characteristic absorption peak at $1665 \mathrm{~cm}^{-1}$ is corresponding to the $\mathrm{C}=\mathrm{O}$ stretching vibration in amide group. Furthermore, the absorption peak at $2937 \mathrm{~cm}^{-1}$ is attributed to the methylene $(\mathrm{C}-\mathrm{H})$ group. The disappearance of the absorption 
peak of $\mathrm{C}=\mathrm{C}$ indicated that the polymerization was completed fully.

To understand the characteristic of adsorption, XPS spectra were used to analyze the change of binding energy before and after adsorption, which were shown in Fig. 8. Fig.8a and 8b were separately developed the $\mathrm{N} 1 \mathrm{~s}$ core-level spectra of the adsorbent before and after $\mathrm{Pb}(\mathrm{II})$ adsorption, in which the binding energy of $399.4 \mathrm{eV}$ can be assigned to nitrogen in the amino groups on the adsorbent surface. ${ }^{21}$ After $\mathrm{Pb}$ (II) adsorption, the binding energy of $\mathrm{N} 1 \mathrm{~s}$ electron becomes $399.9 \mathrm{eV}$, implying that it shifts upward to be $0.5 \mathrm{eV}$. In general, it can be considered as the shift of electronic cloud from nitrogen atom to $\mathrm{Pb}$ (II) ion. $^{22}$

Fig. $8 \mathrm{c}$ and $8 \mathrm{~d}$ show the binding energies of $\mathrm{Pb} 4 \mathrm{f}_{7 / 2}$ and $\mathrm{Pb}$ $4 \mathrm{f}_{5 / 2}$ in the pure lead acetate and in the adsorbent after $\mathrm{Pb}$ (II) adsorption. The former was 139.0 and $143.8 \mathrm{eV}$ and the latter was 137.1 and $141.8 \mathrm{eV}$, respectively. That is to say, the binding energies both $\mathrm{Pb} 4 \mathrm{f}_{7 / 2}$ and $\mathrm{Pb} 4 \mathrm{f}_{5 / 2}$ shift down to the lower energy region, reflecting the increase of the electronic density around $\mathrm{Pb}$ (II) ion and the formation of $\mathrm{Pb}(\mathrm{II})-\mathrm{N}$ coordinate bond.

The binding ability of the adsorbent for metal cations was depended on the amino group $\left(-\mathrm{NH}_{2}\right)$ of the polymer chain. ${ }^{23}$ $\mathrm{N}, \mathrm{N}$-methylenebisacrylamide as a crosslinking agent in polymerization reaction could provide more amino groups. Thereby, it is benefit to metal ion adsorption onto polyacrylamide.

The most important single parameter influencing the sorption capacity is the $\mathrm{pH}$ of adsorption medium. The initial $\mathrm{pH}$ of adsorption medium is related to metal species in solution and the surface properties of the adsorbents in terms of dissociation of functional groups and surface charge. ${ }^{24}$ So it not only affects the adsorption mechanism onto the adsorbent surface, but also influences the nature of the physicochemical interaction of the species in solution and the adsorptive sites of adsorbent.

In the following experiments, the used concentration of lead ion is $100 \mathrm{mg} / \mathrm{L}$, i.e. $\left[\mathrm{Pb}^{2+}\right]$ equals to $4.83 \times 10^{-4} \mathrm{~mol} / \mathrm{L}$, which represents the molarity of lead ion. Due to the solubility product of lead hydroxide being $1.2 \times 10^{-15}$, if the $\left[\mathrm{OH}^{-}\right]$was beyond the limit of $1.57 \times 10^{-6} \mathrm{~mol} / \mathrm{L}$, the precipitation of $\mathrm{Pb}(\mathrm{OH})_{2}$ would be observed ( $\mathrm{pH} \sim 8.2$ ). However, the adsorption to $\mathrm{Pb}$ (II) is very poor at acidic solution (e.g. $\mathrm{pH}<2$ ). If the adsorption of polyacrylamide to $\mathrm{Pb}(\mathrm{II})$ ion belongs to chelation, the lower $\mathrm{pH}$ is benefited to the protonation of absorbent rather than chelation to $\mathrm{Pb}(\mathrm{II})$ ion, and the higher $\mathrm{pH}$ is in favor of the de-protonation and chelation. In addition, due to hydroxide precipitation of metal ion at basic solution, the optimum $\mathrm{pH}$ must be carefully chosen in acidic solution at first. In this study, the optimum $\mathrm{pH}$ was found to be about 5.0 showing in Fig. 9 .

Effect of adsorbent dose on removal percentage of lead ion was listed in Table 1. Percentage of lead ion removal increases from 13 to $96 \%$ when the adsorbent dose per $100 \mathrm{~mL}$ of solution with $100 \mathrm{mg} / \mathrm{L}$ lead ions concentration increases from 0.02 to $0.20 \mathrm{~g}$. The number of adsorption sites or surface area increases with the amount of adsorbent and hence results in a higher percent of metal removal at a high dose. However, the amount of metal ions adsorbed per unit weight of adsorbent $(\mathrm{mg} / \mathrm{g}) \mathrm{dec}-$ reases with increasing the adsorbent dose. This is due to the fact that at higher adsorbent dose the solution ion concentration drops to a lower value and the system reaches equilibrium at lower unit adsorption capacity indicating the adsorption sites

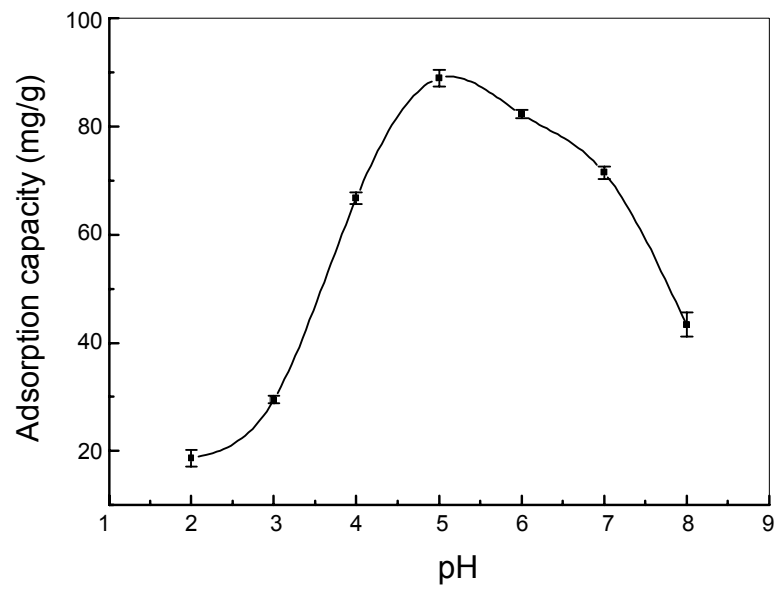

Figure 9. Effect of $\mathrm{pH}$.

Table 1. Effect of adsorbent dose

\begin{tabular}{ccc}
\hline adsorbent dose (g) & $\begin{array}{c}\text { percentage of lead } \\
\text { ion removal (\%) }\end{array}$ & $\begin{array}{c}\text { unit adsorption } \\
\text { capacity }(\mathrm{mg} / \mathrm{g})\end{array}$ \\
\hline 0.02 & 22 & 110 \\
0.05 & 47 & 94 \\
0.10 & 89 & 89 \\
0.15 & 93 & 62 \\
0.20 & 96 & 48 \\
\hline
\end{tabular}

remain unsaturated.

Singling out $20 \sim 30,30 \sim 40,70 \sim 80$ and $100 \sim 150$ meshes of sieves, prepared adsorbent is sieved to collect particles with $0.90 \sim 0.60 \mathrm{~mm}, 0.60 \sim 0.45 \mathrm{~mm}, 0.22 \sim 0.18 \mathrm{~mm}$ and $0.15 \sim 0.10$ $\mathrm{mm}$ of average diameter, respectively. Due to the surface area of the adsorbent being an important parameter for adsorption, thereby, the larger surface area of adsorbent would be expected always. The smaller the particle size the larger the surface area per unit weight of adsorbent and hence higher percentage of metal removal would be reached. Results showed that the following size particles, such as $0.90 \sim 0.60 \mathrm{~mm}, 0.60 \sim 0.45 \mathrm{~mm}$, $0.22 \sim 0.18$ and $0.15 \sim 0.10 \mathrm{~mm}$, correspond to the percentages of lead ion removal being $71 \%, 89 \%, 91 \%$ and $92 \%$, respectively. To filter conveniently, the collected particles with a diameter $0.60 \sim 0.45 \mathrm{~mm}$ were selected for other experiments. Of course, the internal surface is also an effective parameter. As the examination is very difficult to do, we could not obtain this data.

Sorption isotherm describes the behavior interacted between the $\mathrm{Pb}$ (II) ion and adsorbent. The equilibrium data by either theoretical or empirical equations is essential for practical design and operation of adsorption systems. Fig. 10 shows sorption isotherm of $\mathrm{Pb}(\mathrm{II})$ ion on polyacrylamide grafted hydrous ferric oxide adsorbent, and it presents a plot of the adsorption amount $\left(Q_{e}, \mathrm{mg} / \mathrm{g}\right)$ versus the equilibrium $\mathrm{Pb}$ (II) concentration in the solution $\left(C_{\mathrm{e}}, \mathrm{mg} / \mathrm{L}\right)$. Commonly, the gas sorption equilibrium data can be applied to two common isotherm models: the Freundlich and Langmuir model. Although the two isotherm approaches have been widely used to interpret adsorption equilibrium in solution adsorption, the equation is still an empirical in nature. $^{25,26}$ 


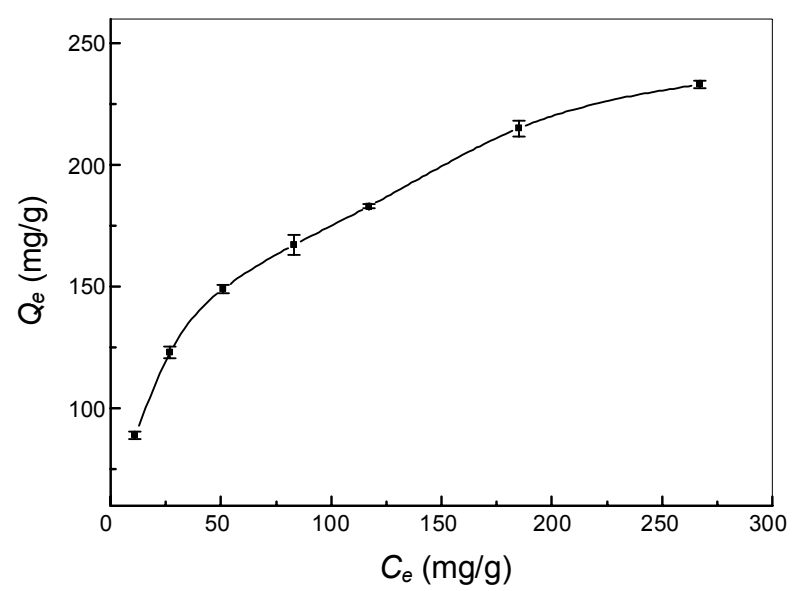

Figure 10. Sorption isotherm of initial concentration of $\mathrm{Pb}(\mathrm{II}): 100 \mathrm{mg} /$ L-400 mg/L; $\mathrm{pH}=5.0$; temperature: $298 \mathrm{~K}$.

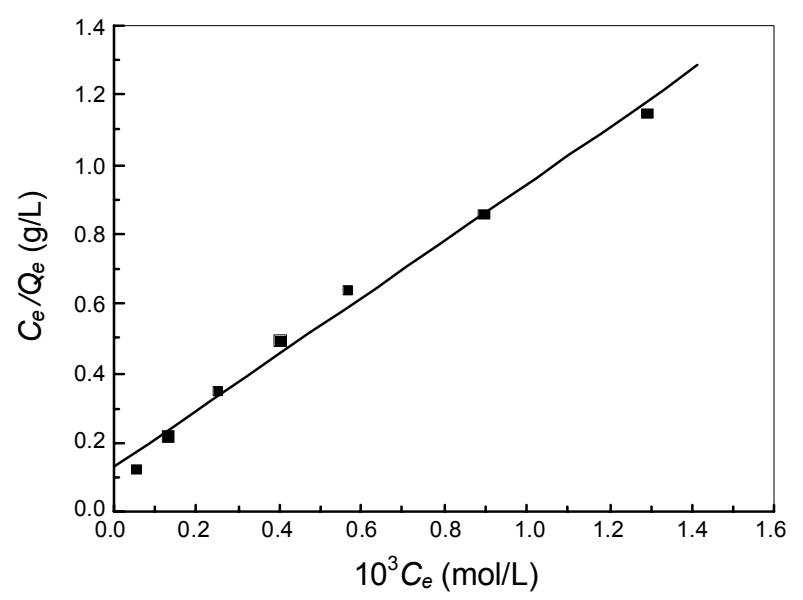

Figure 11. Langmuir isotherms of $\mathrm{Pb}$ (II) adsorption on polyacrylamide grafted hydrous ferric oxide adsorbent at $298 \mathrm{~K}$.

The Langmuir sorption isotherm assumes that the adsorbed layer is monomolecular layer and a completely homogeneous surface with a finite number of identical sites and with negligible interaction between adsorbed molecules, resulting in equal free energies and enthalpies of adsorption. This equation for the Langmuir isotherm is as follows:

$$
Q_{e}=\frac{b Q_{o} C_{e}}{1+b C_{e}}
$$

Linear form of this equation is:

$$
\frac{C_{e}}{Q_{e}}=\frac{1}{b Q_{o}}+\frac{C_{e}}{Q_{o}}
$$

Where $b$ is the Langmuir isotherm constant relative to adsorption energy, $Q_{o}$ is the amount of adsorbate at complete monolayer coverage ( $\left.\mathrm{mol} \mathrm{g}^{-1}\right), Q_{e}$ is the amount of $\mathrm{Pb}$ (II) adsorbed per mass unit of adsorbent at equilibrium $\left(\mathrm{mol} \mathrm{g}^{-1}\right)$ and $C_{e}$ is the equilibrium concentration of remaining lead ions in the solution $(\mathrm{mol} / \mathrm{L})$. The Langmuir isotherm equation was pre-tested in this

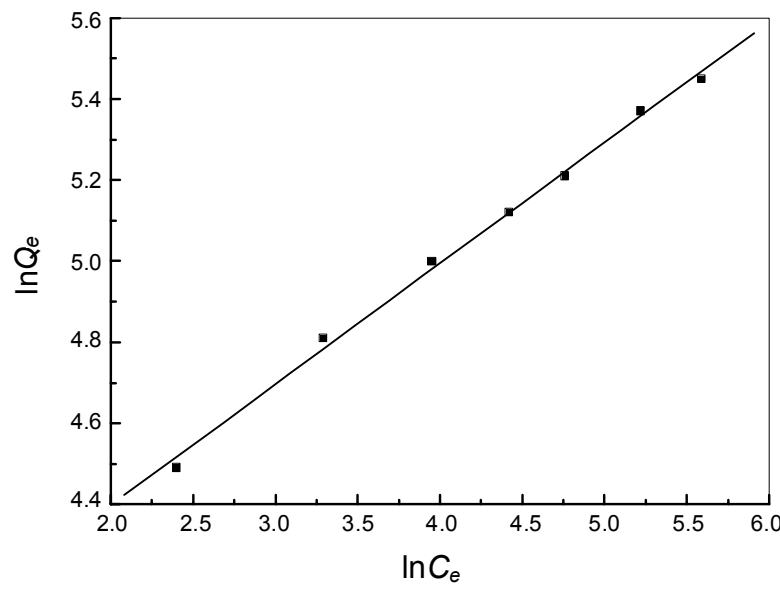

Figure 12. Freundlich isotherms of $\mathrm{Pb}$ (II) adsorption on polyacrylamide grafted hydrous ferric oxide adsorbent at $298 \mathrm{~K}$.

study. The linear relationship of the Langmuir isotherm plot for sorption of $\mathrm{Pb}$ (II) on polyacrylamide grafted hydrous ferric oxide adsorbent was shown in Fig. 11 by plotting $C_{e} / Q_{e}$ versus $C_{e}$. The Langmuir isotherm parameter was determined by least square fit of the sorption data in Fig. 11. $Q_{o}$ and $b$ were determined from the slope, intercept of the Langmuir isotherm plot. The Langmuir maximum adsorption capacity $Q_{o}$ and the Langmuir isotherm constant $b$ were found to be $1.23 \times 10^{-3} \mathrm{~mol} / \mathrm{g}(254.6$ $\mathrm{mg} / \mathrm{g}$ ) and 6177 at $298 \mathrm{~K}$, respectively. As it may be observed a statistically significant linearity using the Langmuir model to describe lead ions $\left(\mathrm{R}^{2}=0.99504\right)$ sorption process (Fig. 11). $\mathrm{R}^{2}$ is linear correlation coefficient.

The Freundlich isotherm was derived by assuming an exponential decay energy distribution function inserted in the Langmuir equation. The Freundlich equation is applicable to highly heterogeneous surfaces, and an adsorption isotherm lacking stabilization indicates a multi-layer adsorption. ${ }^{27}$ The Freundlich equation may be represented by

$$
Q_{e}=K_{F} C_{e}^{1 / n}
$$

$Q_{e}$ is the adsorption amount $(\mathrm{mg} / \mathrm{g}), C_{e}$ is the equilibrium metal ion concentration in the solution $(\mathrm{mg} / \mathrm{L})$. A linear relationship of the Freundlich equation will give the constants $K_{F}$ and $n$.

$$
\ln Q_{e}=\frac{1}{n} \ln C_{e}+\ln K_{F}
$$

Based on Eq. (5), a straight line was obtained by plotting $\ln Q_{e}$ versus $\ln C_{e}$, showing in Fig.12, which was a logarithmic plot of the Freundlich isotherm for the adsorption of $\mathrm{Pb}(\mathrm{II})$. It was clearly that the Freundlich isotherm provides a good representation for this study $\left(\mathrm{R}^{2}=0.99811\right) . K_{F}$ and $n$ are empirical coefficients determined from the intercepts and slopes by the least square method, obtaining to be 44.8 and 3.35 , respectively. Although both isotherm models were of linear relationship, the Freundlich model may be a better fit than the Langmuir model, according to the correlation coefficients at $298 \mathrm{~K}$.

A comparative study with other adsorbents for the maximum removal amount of $\mathrm{Pb}$ (II) was listed in Table 2. Results showed 
Table 2. Removal capacities $\left(Q_{o}\right)$ of $\mathrm{Pb}(\mathrm{II})$ ion by various adsorbents

\begin{tabular}{lrc}
\hline \multicolumn{1}{c}{ Adsorbent } & $Q_{\mathrm{o}}(\mathrm{mg} / \mathrm{g})$ & Reference \\
\hline PHEMA/chitosan membranes & 68.81 & {$[28]$} \\
Wheat bran & 87 & {$[29]$} \\
Penicillium simplicissimum & 152.6 & {$[30]$} \\
Palm shell activated carbon & 95.2 & {$[31]$} \\
Activated phosphate & 155 & {$[32]$} \\
HAp (50 wt \%)/PAAm gel & 178 & {$[33]$} \\
Polyacrylamide/zeolite composite & 58 & {$[34]$} \\
HAp (50 wt \%)/PU composite foam & 150 & {$[35]$} \\
Polyacrylamide grafted hydrous ferric oxide & 254.6 & present \\
adsorbent & & work \\
\hline
\end{tabular}

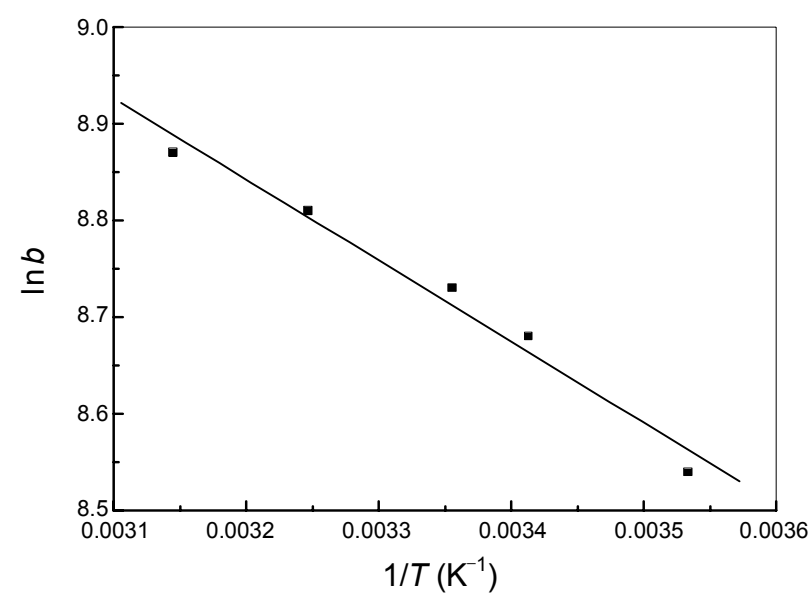

Figure 13. Plot of $\ln b$ against reciprocal temperature for $\mathrm{Pb}$ (II) adsorption on polyacrylamide grafted hydrous ferric oxide adsorbent.

that polyacrylamide grafted hydrous ferric oxide is, indeed, an excellent adsorbent for removing $\mathrm{Pb}$ (II) ion from wastewater.

To understand easily the effect of temperature on the adsorption of $\mathrm{Pb}$ (II) ion, the thermodynamic parameters have been studied at 283, 293, 298, 308and $318 \mathrm{~K}$, respectively, using the following equations in which $b$ is the Langmuir constant, $\Delta G$ is the standard Gibbs energy change, $\Delta H$ is the standard enthalpy change and $\Delta S$ the standard entropy change.

$$
\begin{aligned}
& \Delta G=-R T \ln b \\
& \Delta G=\Delta H-T \Delta S \\
& \ln b=\frac{\Delta S}{R}-\frac{\Delta H}{R T}
\end{aligned}
$$

Where, $\Delta G, \Delta H$ and $\Delta S$ can be also calculated from graphical interpretation based on the experimental data. That is, using the slope and intercept by plotting $\ln b$ versus $1 / T$ (Van't Hoff equation), showing in Fig. 13 to calculate $\Delta H$ and $\Delta S$. Results show that in the narrow temperature range of $283-318 \mathrm{~K}$ the free energy change $(\Delta G)$ is vary little and no changes in $\Delta H(6.96 \mathrm{~kJ} /$ $\mathrm{mol})$ and $\Delta S(95.79 \mathrm{~J} / \mathrm{mol} \mathrm{K})$, implying that both physical and chemical absorptions are existed in this study.

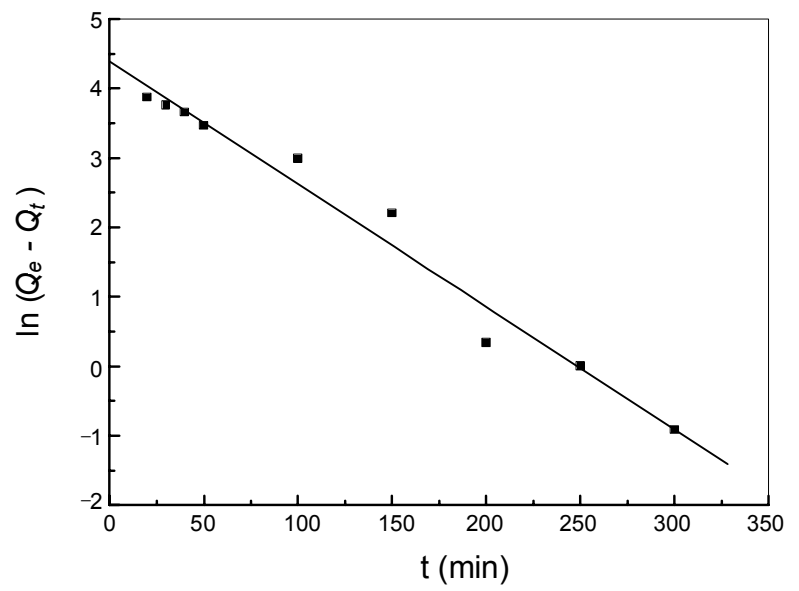

Figure 14. Lagergren first-order kinetic plots for the adsorption of $\mathrm{Pb}$ (II) on polyacrylamide grafted hydrous ferric oxide adsorbent at $298 \mathrm{~K}$.

The positive of $\Delta H$ indicates an endothermic for the adsorption process; whereas the negative of $\Delta G$ means a spontaneous process of $\mathrm{Pb}$ (II) adsorption. The positive of $\Delta S$ indicates a more random state owning to the liberation of water molecule during chelation process. $^{36}$

The kinetics for the adsorption of $\mathrm{Pb}$ (II) on polyacrylamide grafted hydrous ferric oxide adsorbent has been studied in aqueous solution containing $100 \mathrm{mg} / \mathrm{L} \mathrm{Pb}(\mathrm{II})$ ion at $\mathrm{pH} 5.0$ with time ranging from 20 to $300 \mathrm{~min}$. The rate of sorption process was affected by several parameters such as the structural of adsorbent, properties and concentration of the metal ion, chelate formation between metal ion and adsorbent, and so on. The adsorption kinetics of $\mathrm{Pb}(\mathrm{II})$ on polyacrylamide grafted hydrous ferric oxide adsorbent was obeyed to the Lagergren first-order and pseudo-second-order, according to Eqs (9) and (10), respectively.

$$
\begin{aligned}
& \ln \left(Q_{e}-Q_{t}\right)=\ln Q_{e}-k_{l} t \\
& \frac{t}{Q_{t}}=\frac{1}{k_{2} Q_{e}^{2}}+\frac{t}{Q_{e}}
\end{aligned}
$$

Where $Q_{e}$ and $Q_{t}\left(\mathrm{mg} \mathrm{g}^{-1}\right)$ are the amounts of $\mathrm{Pb}$ (ii) adsorbed on the adsorbent at equilibrium and at various times $t . k_{I}\left(\mathrm{~min}^{-1}\right)$ is the rate constant of the Lagergren-first-order model and $k_{2}$ $\left(\mathrm{g} \mathrm{mg}^{-1} \mathrm{~min}^{-1}\right)$ is the rate constant of the pseudo second-order model for adsorption process. The plot of $\ln \left(Q_{e}-Q_{t}\right)$ against $t$ was fitted the Lagergren-first-order model (see Fig. 14) and the plot of $t / Q_{t} v s t$ for the pseudo-second-order model (see Fig.15), in which the rate constant for former was $\mathrm{k}_{1}=1.77 \times 10^{-2} \mathrm{~min}^{-1}$ and for the latter $k_{2}=2.76 \times 10^{-4} \mathrm{~g} \mathrm{mg}^{-1} \mathrm{~min}^{-1}$, respectively. However, the value of correlation coefficient $\mathrm{R}^{2}$ for the former $(0.99864)$ was better than the latter $(0.98789)$. The pseudo second-order model was based on the assumption that the ratelimiting step could be a chemical sorption involving valence forces through sharing or exchange of electrons between adsorbent and adsorbate. Thereby, it could reflect the adsorption behavior involving the valence forces through sharing electrons between metal ion and adsorbent. ${ }^{37}$ 


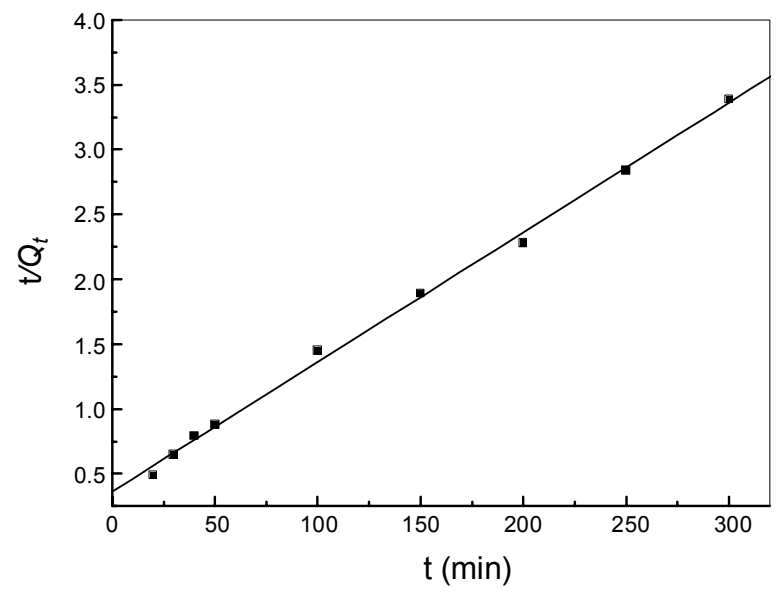

Figure 15. Pseudo-second-order kinetic plots for the adsorption of $\mathrm{Pb}$ (II) on polyacrylamide grafted hydrous ferric oxide adsorbent at $298 \mathrm{~K}$.

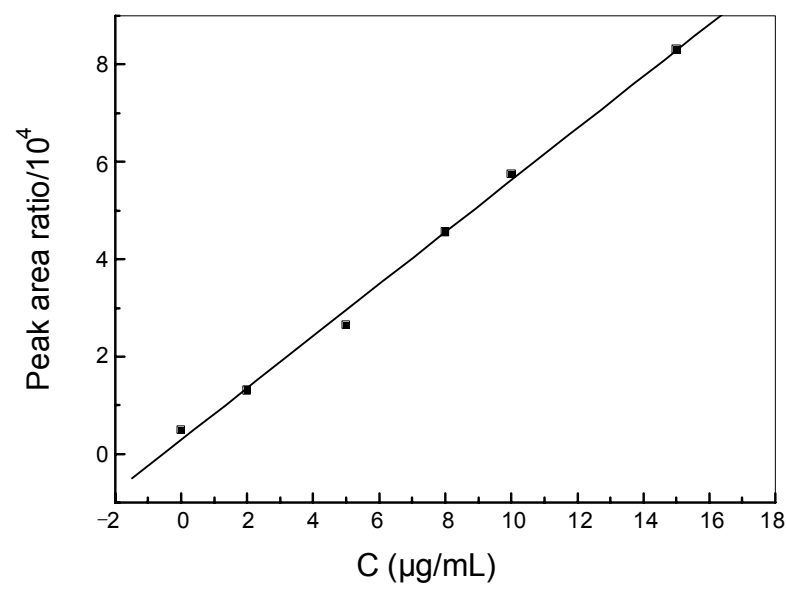

Figure 16. The calibration curve $(y=a x+b)$ is constructed by plotting the peak area ratio $(y)$ of the standards versus the amount of acrylamide $(x)$. The linear fit equation for is: $y=5338.6 x+2832.1$.

In general, the content of metal ion in industrial wastewater was less than $50 \mathrm{mg} / \mathrm{L}$. Thus, in this work a solution of $50 \mathrm{mg} / \mathrm{L}$ metal ion was used to examine the removal percentage for $\mathrm{Ag}^{+}$, $\mathrm{Cd}^{2+}, \mathrm{Pb}^{2+} \mathrm{Co}^{2+}, \mathrm{Ni}^{2+}$, and $\mathrm{Cu}^{2+}$ ions in which $0.1 \mathrm{~g}$ of polyacrylamide grafted hydrous ferric oxide adsorbent was used. Results showed that for $\mathrm{Ag}^{+}, \mathrm{Cd}^{2+}, \mathrm{Pb}^{2+}$ ions the removal percentage were near to $100 \%$, and for $\mathrm{Co}^{2+}, \mathrm{Ni}^{2+}, \mathrm{Cu}^{2+}$ ions were $96 \%, 94 \%$, and $98 \%$, respectively.

Place $0.1 \mathrm{~g}$ of polyacrylamide grafted hydrous ferric oxide adsorbent into $600 \mathrm{~mL}$ of mixed solution containing $\mathrm{Ag}^{+}, \mathrm{Co}^{2+}$, $\mathrm{Cd}^{2+}, \mathrm{Pb}^{2+}, \mathrm{Ni}^{2+}$ and $\mathrm{Cu}^{2+}$ ions in which every ion concentration was chosen as $50 \mathrm{mg} / \mathrm{L}$. The adsorption amounts were found to be $\mathrm{Ag}^{+} 27.3 \mathrm{mg} / \mathrm{g}, \mathrm{Co}^{2+} 16.8 \mathrm{mg} / \mathrm{g}, \mathrm{Cd}^{2+} 28.2 \mathrm{mg} / \mathrm{g}, \mathrm{Pb}^{2+} 31.1$ $\mathrm{mg} / \mathrm{g}, \mathrm{Ni}^{2+} 14.7 \mathrm{mg} / \mathrm{g}$, and $\mathrm{Cu}^{2+} 15.9 \mathrm{mg} / \mathrm{g}$. It can be seen roughly that the adsorption behavior was relative to the property of metal ion; that is, highly positive charge and smaller ionic radii would be benefit to the adsorption. ${ }^{38}$

Due to acrylamide being is a toxic monomer, ${ }^{39}$ its residual amount in polymer must be strictly controlled. The commonly used technique is chromatography for determination of acryl- amide ${ }^{40}$ The calibration curve of acrylamide by HPLC with UV detector at $205 \mathrm{~nm}$ was given in Fig. 16. In the range of $1-15 \mu \mathrm{g} /$ $\mathrm{mL}$ the regression equation $\mathrm{y}=5338.6 \mathrm{x}+2832.1$ exhibits a well linear relationship with a correlation coefficient of 0.9982 . Using this method to detect the product, the amount of acrylamide was less than $1.36 \mu \mathrm{g} / \mathrm{mL}$, i.e. $0.0136 \%$. This result showed again that the polyacrylamide grafted hydrous ferric oxide adsorbent by the proposed technique has an excellent property and could be applied in wastewater treatment.

\section{Conclusion}

In this study, polyacrylamide grafted hydrous ferric oxide adsorbent composite has been synthesized by using glow discharge electrolysis plasma. The following parameters would be the optimization conditions: applied power $40 \mathrm{~W}$, discharge time 14 min, post polymerization temperature $85^{\circ} \mathrm{C}$, post polymerization time $150 \mathrm{~min}, 1.5 \mathrm{~g}$ of hydrous ferric oxide gel and $0.6 \mathrm{~g}$ of crosslinking agent. The adsorption of $\mathrm{Pb}$ (II) onto polyacrylamide grafted hydrous ferric oxide adsorbent could be a chelate process. Langmuir and Freundlich adsorption isotherm models were employed to describe the $\mathrm{Pb}(\mathrm{II})$ adsorption onto polyacrylamide grafted hydrous ferric oxide adsorbent at $298 \mathrm{~K}$. According to the Langmuir isotherm, the maximum adsorption capacity for $\mathrm{Pb}$ (II) of the adsorbent was $254.6 \mathrm{mg} / \mathrm{g}$. The Freundlich model fits the experimental data better than the Langmuir model. Thermodynamic parameters suggested that the adsorption process was a spontaneous process and endothermic in nature. The pseudo-second-order rate model accurately describes the kinetics of adsorption.

Acknowledgments. This work was supported in part by the Key Project of Science and Technology of Education Ministry (00250), the Natural Science Foundation of Gansu Province (3ZS041-A25-028), the Project of KJCXGC-01, NWNU, and Gansu Key Lab of Polymer Materials, China.

\section{References}

1. Smara, A.; Delimi, R.; Chainet, E.; Sandeaux, J. Sep. Purif. Technol. 2007, 57, 103.

2. Chen, A. H.; Liu, S. C.; Chen, C. Y.; Chen, C. Y. J. Hazard. Mater. 2008, 154, 184.

3. Matsumoto, N.; Uemoto, H.; Saiki, H. Water Res. 2007, 41, 2541.

4. Ng, J. C. Y.; Cheung, W. H.; McKay, G. Chemosphere 2003, 52, 1021.

5. Deng, S. B.; Bai, R. B.; Chen, J. P. Langmuir 2003, 19, 5058.

6. Al-Faqih, L.; Johnson, P. D.; Allen, S. J. Bioresour. Technol. 2008, 99, 1394.

7. Sengupta, S. K.; Singh, R.; Srivastava, A. K. Indian J. Chem. Sect. $A$ 1998, 37, 558.

8. Gao, J. Z.; Wang, A. X.; Fu, Y.; Wu, J. L.; Ma, D. P.; Guo, X.; Li, Y.; Yang, W. Plasma Sci. Technol. 2008, 10, 30.

9. Gao, J. Z.; Guo, X.; Ma, D. P.; Yang, W. Plasma Sci. Technol. 2007, 9, 431.

10. Gao, J. Z. Pak. J. Biol. Sci. 2006, 9, 323.

11. Tezuka, M.; Iwasaki, M. Plasma \& Ions 1999, 1, 23.

12. Lu, Q. F.; Yu, J.; Gao, J. Z. J. Hazard. Mater. 2006, 136, 526.

13. Gao, J. Z.; Yu, J.; Lu, Q. F.; He, X. Y.; Yang, W.; LI, Y.; Pu, L. M.; Yang, Z. M. Dyes \& Pigments 2008, 76, 47.

14. Harada, K.; Iwasaki, T. Nature 1974, 250, 426. 
15. Harada, K.; Suzuki, S. Nature 1977, 266, 275.

16. Sengupta, S. K.; Sandhir, U.; Misra, N. J. Polym. Sci. Part A 2001, 39, 1584.

17. Wang, A. X.; Gao, J. Z.; Yuan, L.; Yang, W. Plasma Chem. Plasma Process 2009, 29, 387.

18. Gao, J. Z.; Fu, Y.; Wang, A. X.; Wu, J. L.; Li, Y.; Yang, W. Chem. J. Internet 2008, 10, 41.

19. Gao, J. Z.; Wang, A. X.; Li, Y.; Fu, Y.; Wu, J. L.; Wang, Y. D.; Wang, Y. J. React. Funct. Polym. 2008, 68, 1377.

20. Gao, J. Z.; Wang, Y. D.; Wang, A. X.; Wang, Y. J.; Li, Y.; Fu, Y.; Wu, J. L. Chin. J. Appl. Chem. (Ch) 2009, 26, 282.

21. Sun, S. L.; Wang, L.; Wang, A. Q. J. Hazard. Mater. 2006, 136, 930.

22. Guan, H. M.; Cheng, X. S. Polym. Adv. Technol. 2004, 15, 89.

23. Dambies, L.; Guimon, C.; Yiacoumi, S.; Guibal, E. Colloids and Surf. A 2001, 177, 203.

24. Sheng, P. X.; Ting, Y. P.; Chen, J. P.; Hong, L. J. Colloid Interface Sci. 2004, 275, 131.

25. Deng, S. B.; Ting, Y. P. Water Res. 2005, 39, 2167.

26. Amarasinghe, B. M.; Williams, R. A. Chem. Eng. J. 2007, 132, 299.

27. Li, Y. H.; Di, Z. C.; Ding, J.; Wu, D. H.; Luan, Z. K.; Zhu, Y. Q. Water Res. 2005, 39, 605.
28. Genc, O.; Soysal, L.; Bayramoglu, G.; Arica, M. Y.; Bektas, S. J. Hazard. Mater. 2003, 97, 111.

29. Bulut, Y.; Baysal, Z. J. Envfer. Manage. 2006, 78, 107.

30. Li, X. M.; Liao, D. X.; Xu, X. Q.; Yang, Q.; Zeng, G. M.; Zheng, W.; Guo, L. J. Hazard. Mater. 2008, 159, 610.

31. Issabayeva, G.; Aroua, M. K.; Sulaiman, N. M. N. Bioresour. Technol. 2006, $97,2350$.

32. Mouflih, M.; Aklil, A.; Sebti, S. J. Hazard. Mater. 2005, 119, 183.

33. Jang, S. H.; Jeong, Y. G.; Min, B. G.; Lyoo, W.S.; Lee, S. C. J. Hazard. Mater. 2008, 159, 294.

34. Ulusoy, U.; Simsek, S. J. Hazard. Mater. 2005, 127, 163.

35. Jang, S. H.; Min, B. G.; Jeong, Y. G.; Lyoo, W. S.; Lee, S. C. J. Hazard. Mater. 2008, 152, 1285.

36. Malkoc, E.; Nuhoglu, Y. Sep. Purif. Technol. 2007, 54, 291.

37. Chen, A. H.; Liu, S. C.; Chen, C. Y. J. Hazard. Mater. 2008, 154, 184.

38. Manju, G. N.; Krishnan, K. A.; Vinod, V. P.; Anirudhan, T. S. J. Hazard. Mater. 2002, 91, 221.

39. Gertz, C.; Klostermann, S. Eur. J. Lipid Sci. Technol. 2002, 104, 762.

40. Paleologos, E. K.; Kontominas, M. G. J. Chromatogr. A 2005, $1077,128$. 